\title{
Dynamic and Thermodynamic Impacts of the Winter Arctic Oscillation on Summer Sea Ice Extent ${ }^{\circ}$
}

\author{
HYO-SEOK PARK \\ Korea Institute of Geoscience and Mineral Resources, Daejeon, South Korea \\ ANDREW L. STEWART \\ Department of Atmospheric and Oceanic Sciences, University of California, Los Angeles, Los Angeles, California \\ JUN-HYEOK SON \\ Department of Atmospheric Sciences, Pusan National University, Busan, South Korea
}

(Manuscript received 6 February 2017, in final form 8 November 2017)

\begin{abstract}
Arctic summer sea ice extent exhibits substantial interannual variability, as is highlighted by the remarkable recovery in sea ice extent in 2013 following the record minimum in the summer of 2012. Here, the mechanism via which Arctic Oscillation (AO)-induced ice thickness changes impact summer sea ice is explored, using observations and reanalysis data. A positive $\mathrm{AO}$ weakens the basin-scale anticyclonic sea ice drift and decreases the winter ice thickness by 15 and $10 \mathrm{~cm}$ in the Eurasian and the Pacific sectors of the Arctic, respectively. Three reanalysis datasets show that the upward surface heat fluxes are reduced over wide areas of the Arctic, suppressing the ice growth during the positive AO winters. The winter dynamic and thermodynamic thinning preconditions the ice for enhanced radiative forcing via the ice-albedo feedback in late spring-summer, leading to an additional $10 \mathrm{~cm}$ of thinning over the Pacific sector of the Arctic. Because of these winter AO-induced dynamic and thermodynamics effects, the winter AO explains about $22 \%$ $(r=-0.48)$ of the interannual variance of September sea ice extent from 1980 to 2015.
\end{abstract}

\section{Introduction}

The Arctic sea ice extent and thickness have been rapidly decreasing in recent decades (Kwok and Rothrock 2009; Laxon et al. 2013; Renner et al. 2014), but also exhibit substantial interannual variability. In the past few decades, there were several years that marked record lows in the summer sea ice extent: the summers of 2007, 2012, and 2016 highlight the rapidly diminishing Arctic sea ice associated with climate change (Döscher et al. 2014; Cullather et al. 2016). However, there were notable rebounds in sea ice extent, such as the $30 \%$ rebound in 2013 (Tilling et al. 2015). It has previously been hypothesized that the positive

\footnotetext{
T) Supplemental information related to this paper is available at the Journals Online website: https://doi.org/10.1175/JCLI-D-170067.s1.

Corresponding author: Hyo-Seok Park, hspark@kigam.re.kr
}

Arctic Oscillation (AO)-induced sea ice thinning in winter can impact the summer sea ice extent (Rigor et al. 2002; Holland and Stroeve 2011). A recent study also found that the years of anomalously small summer sea ice extent have often followed winter AO-induced ice drift away from the Arctic coast since 1991-92 (Williams et al. 2016). The importance of winter sea ice preconditioning in the prediction of the following summer sea ice extent is supported by climate models (e.g., Chevallier and Salas-Mélia 2012; Day et al. 2014), although the predictability is dependent on the sea ice model physics (Blanchard-Wrigglesworth et al. 2015).

There remains some ambiguity regarding the impact of the winter $\mathrm{AO}$ on September sea ice extent because of several other phenomena occurring in the spring and summer. For example, anomalously strong downward longwave radiation in spring can accelerate sea ice melting and have contributed to record minima in the Arctic summer sea ice extent (Serreze et al. 2003; Graversen et al. 2011; Kapsch et al. 2013). An anticyclonic 
wind-induced ice export through Fram Strait in spring and summer, which is anticorrelated with Arctic cyclone frequency (Screen et al. 2011), is also suggested as an influential factor for summer sea ice extent (Smedsrud et al. 2017). In summer, shortwave radiation at the surface, which is sensitive to the changes in cloud cover, can effectively change sea ice concentration in a matter of weeks (Kay et al. 2008). Because of these springsummer weather activities, the 6-7-month lagged seasonal relationship between winter sea ice conditions and September sea ice extent is ambiguous (e.g., BlanchardWrigglesworth et al. 2011).

In this study, we investigate the mechanism via which the winter AO impacts summer sea ice using reanalysis products, and quantify the relative roles of dynamic and thermodynamic forcing. Specifically, we quantify the wind-driven sea ice thinning during the positive $\mathrm{AO}$ winters over a 36 -yr period, which is 14 years longer than the observational records used by Rigor et al. (2002). Then, utilizing two reanalysis datasets, we quantify anomalous thermodynamic forcing associated with the AO between the winter and the following summer. First, we examine surface heat flux anomalies during the positive AO winters to identify possible thermodynamic effects on sea ice growth. Second, we identify the relationship between winter $\mathrm{AO}$ and surface radiative forcing in subsequent spring and summer, and particularly net shortwave radiation that can effectively enhance ice thickness and concentration anomalies via the icealbedo feedback (Bushuk et al. 2017). The rest of this paper is organized as follows. Section 2 describes the data and methodology used in our analysis. Then in sections 3 and 4, we examine the positive AO-induced sea ice thickness changes in winter using observation data and reanalysis data. In section 5 , we elucidate the dependence of spring and summer radiative forcing on the preceding winter AO using multiple reanalysis datasets. We provide our discussion and conclusions in section 6 .

\section{Data and methods}

a. Data

For sea ice thickness, sea ice velocity, ice flux divergence, upper-ocean temperature, and ocean heat flux-induced ice melting in the Arctic, we used data from the Pan-Arctic Ice Ocean Modeling and Assimilation System (PIOMAS; Zhang and Rothrock 2003), which consists of a 12-category thickness and enthalpy distribution sea ice model coupled with the Parallel Ocean Program (POP) ocean model (Smith et al. 2010). The data are provided as monthly means spanning January 1978-December 2015. The grid is configured in generalized curvilinear coordinates with $360 \times 120$ horizontal grid points. To drive the ice-ocean coupled model, surface wind, surface air temperature, and downward radiations at the surface are specified from the NCEP-NCAR reanalysis (NNR; Kalnay et al. 1996). Satellite-derived sea ice concentration was assimilated into PIOMAS, which substantially improves the simulated ice thickness and ice motion (Lindsay and Zhang 2006). Additionally, the wind-ice drag coefficient in the model was adjusted to improve the correspondence between the simulated ice velocity and that measured by buoys (Zhang and Rothrock 2003). For sea level pressure and surface winds, we present results from NNR, because this product is used to force the ice drift in PIOMAS.

To validate the PIOMAS-simulated ice drift velocity, we utilized the buoy tracks provided by International Arctic Buoy Program (IABP) that spans 1979 to 2015 (available at ftp://iabp.apl.washington.edu/pub/IABP/ C/). IABP buoy drift data are provided in 3-hourly increments between 1979 and 2007, and hourly from 2008 onward. We calculated the drift velocity of every buoy track as the orthodromic distance between buoy positions divided by a time interval of $6 \mathrm{~h}$, or, in case of missing data, not longer than $48 \mathrm{~h}$. After calculating the drift velocity of each buoy, we interpolated the drift velocity into a Gaussian grid with a horizontal resolution of $2.0^{\circ} \times 2.0^{\circ}$. Because of the limited spatial temporal coverage of buoys, the monthly mean ice velocity data covers about $30 \%$ of the $2.0^{\circ} \times 2.0^{\circ}$ grids over the Pacific sector of the Arctic, where buoys are most abundant. This ice velocity field is used to validate the interannual variation of the zonal ice drift velocity, averaged over the Pacific sector of the Arctic. To validate the twodimensional (longitude-latitude) ice drift pattern during positive AO winters, we utilized an optimally interpolated ice velocity dataset, which is interpolated into 28 grid points over the entire Arctic that spans 1979 to 2011 (ftp://iabp.apl.washington.edu/pub/IABP/D/). From 2012 to 2015, we interpolated the ice velocity data to 28 grid points using a two-dimensional interpolation function provided by Matlab.

To present the observational evidence of sea ice thickness changes during the strong $\mathrm{AO}$ winters, we utilized the estimates of ice thickness from CryoSat-2 (Wingham et al. 2006). The data are provided as monthly means from the winter of 2010-11 to the present. We use CryoSat-2 to compute the growth of ice for the winters of 2011-12 and 2012-13. Laxon et al. (2013) showed that the spatial pattern of sea ice thickness estimated from CryoSat-2 data is generally consistent with that of previous satellite and submarine measurements (Kwok and Rothrock 2009). To further test the robustness of the ice thickness response to AO, we also examine the Ocean Re-Analysis Pilot 5 (ORAP5) (Tietsche et al. 
2015; Zuo et al. 2015), a global eddy-permitting ocean reanalysis produced by the European Centre for Medium-Range Weather Forecasts (ECMWF), spanning January 1978 to December 2013. The sea ice model is run with a viscous plastic rheology and is coupled to the ocean model, Nucleus for European Modelling of the Ocean (NEMO), version 3.4.1 (Madec 2016). Forcing fields for ORAP5 are derived from the ECMWF interim reanalysis (ERAI) (Dee et al. 2011) and satellite-derived sea ice concentration was assimilated into ORAP5.

To estimate the shortwave and longwave radiative forcing in the Arctic, we utilized three independent reanalysis datasets: 1) NNR, 2) ERAI, and 3) the U.S. National Aeronautics and Space Administration (NASA) Modern-Era Retrospective Analysis for Research and Applications (MERRA) reanalysis (Rienecker et al. 2011). ERAI performs best in simulating the Arctic surface radiative fluxes among various reanalysis products (Zib et al. 2012). In a study that forced an ice/ocean model using various reanalysis products, MERRA turned out to perform best in simulating the Arctic sea ice thickness (Lindsay et al. 2014). Sea ice concentration (SIC) and sea ice extent data are obtained from the National Snow and Ice Data Center (NSIDC). For the winter AO, we used the AO index from the definition of Thompson and Wallace (1998), which is provided by the Climate Prediction Centre (CPC). The AO time series is normalized by the standard deviation of the monthly index. CPC employs the NNR's sea level pressure to calculate the AO index. We reproduced the AO index using ERAI and found that the monthly time series of AO index from ERAI is almost identical to that of NNR (correlation coefficient, $r \approx 0.98$, not shown). In analyzing each of the datasets mentioned above, we used data for the 36-yr period spanning from 1979-80 to 201415. Several variables provided by MERRA data start from the year 1980, so in our analysis of MERRA we used a 35-yr period spanning from 1980-81 to 2014-15. The ORAP-5 output spans from 1979-80 to 2012-13 (a 34-yr period), which is 2 years shorter than PIOMAS.

\section{b. Methods}

In this study, we define the Arctic winter as a 4-month period from December to March (DJFM), during which solar insolation is very weak and sea ice extent is largest. The winters of anomalously positive phase of $\mathrm{AO}$ are defined as those years in which the DJFM average AO index exceeds the $\pm 0.5 \sigma$ anomaly threshold, where $\sigma$ is the standard deviation. The results we present are qualitatively consistent in the case when the $\pm 1.0 \sigma$ anomaly threshold is used. Composites of SIC, SLP, 10-m winds, sea ice thickness, sea ice motion, ice flux divergence, ocean heat flux-induced ice melting, and surface radiative/heat fluxes are obtained for years of positive winter AO. Sea ice thickness and SIC show decreasing trends over the 36-yr time series, whereas radiative fluxes and ocean heat flux-induced ice melting in the Arctic show slightly increasing trends. These trends are approximately linear (SIC trend is not necessarily linear as discussed above), and were removed prior to constructing the composites. A statistical significance test was performed for each seasonally averaged variable with a Monte Carlo method. Specifically, composites were performed 500 times with randomly selected subsamples from the 36 seasonal-mean values. Based on the distribution of the resulting composites, $95 \%$ confidence levels were calculated.

\section{Observed effects of winter AO on summer sea ice}

Figure 1a shows the interannual variability of the winter AO. Comparison between Figs. 1a and 1b show that the anomalously small September sea ice extent is typically preceded by positive AO in winter. Note that the record minima of sea ice extent in the summers of 2007 and 2012 are associated with positive AO in the preceding winters. Conversely, the recovery of the sea ice extent in 2013 is associated with negative winter AO. The correlation coefficient between the winter $\mathrm{AO}$ and the September sea ice extent (15-yr running average is subtracted) throughout the 36 years is generally high (Fig. 1c). Consistent with Williams et al. (2016), this correlation coefficient has been statistically significant since the early 1990s, reaching as high as 0.82 around year 2000. The years $2000-01$ show a particularly strong correlation because the 15 -yr window happens to avoid anomalous years like 1992 and 2010. While the winter AO was near neutral or slightly negative from 1996 to 2006 (Wang et al. 2009), the 15-yr period about the year 2000 spans from 1993 to 2007, containing 5 identified positive AO events (1993, 1995, 2000, 2002, and 2007). Although the relationship has weakened as a result of the summer of 2010 (Stroeve et al. 2011), the correlation coefficients over the past couple of decades are still around -0.6. The 36-yr correlation from 1980 to 2015 between the winter AO and September sea ice extent is -0.48 (Fig. 1d), which explains more than $20 \%$ of the interannual variance. However, the correlation coefficient decreases down to -0.33 in the case when the September sea ice extent anomalies are defined as the deviation from a least squares linear regression. The sensitivity of correlation coefficients to the methods of removing the decadal trend and to the averaging period is briefly summarized in Table 1 .

The statistically significant correlation between winter $\mathrm{AO}$ and summer sea ice extent suggests that the winter 
(a) Winter Arctic Oscillation (AO) index

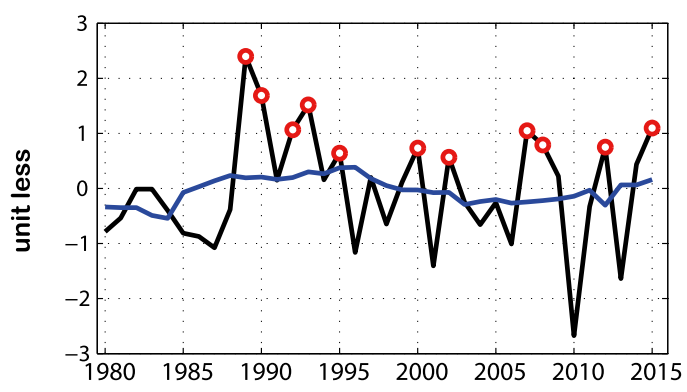

(b) September sea ice extent

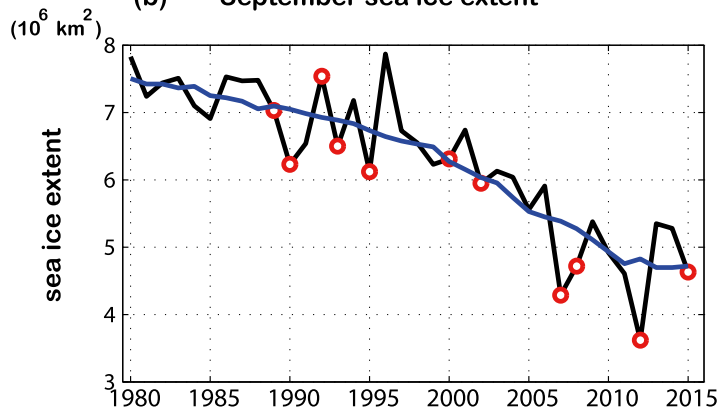

(c) 15-year running correlation

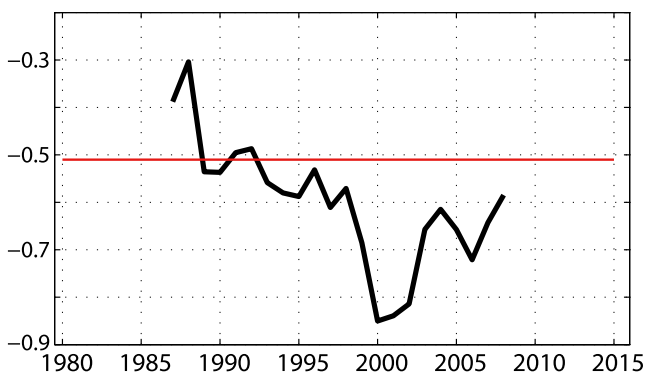

$\left(10^{6} \mathrm{~km}^{2}\right) \quad$ (d) $36-$ year correlation

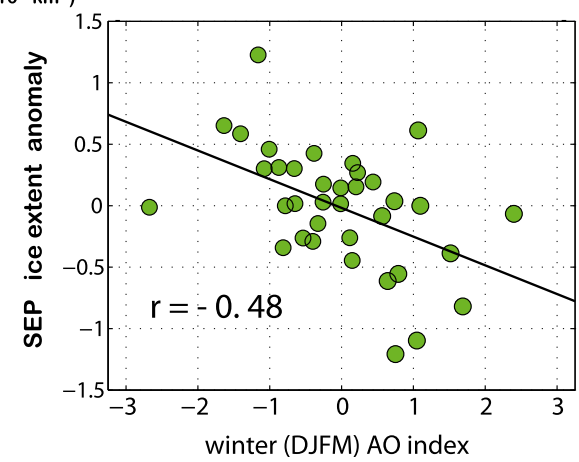

FIG. 1. The interannual variability of (a) winter (DJFM) AO index and (b) NSIDC September sea ice extent $\left(\mathrm{km}^{2}\right)$ from 1980 to 2015. The red dots indicate the years when the winter AO index is larger than 0.5 standard deviations. (c) The 15-yr running-window correlation and (d) 36-yr interannual correlation between the winter AO index and the anomalous September sea ice extent. The blue lines in (a) and (b) are 15-yr running averages. Correlation coefficients below the red line in $(c)$ are statistically significant $(p<0.05)$. The sea ice extent anomalies are defined as deviations from the 15-yr running average: the correlation coefficient in year 2000 is calculated using the time period 1993-2007. We use the convention that the winter of 2010 ends in March 2010.

AO might substantially influence winter sea ice thickness. In winter, from December to March, sea ice grows continuously, and the growth rate is particularly high in the marginal ice zone: up to $1.5-1.8 \mathrm{~m}$ over this 4-month period (Fig. 2). For example, the observed ice thickness from CryoSat-2 shows that the ice growth is generally within 1.0-1.2 m over the Russian sector of the Arctic (Barents-Kara-Laptev-East Siberian Seas) in the winter of 2011-12 (Fig. 2a), during which AO was positive. In the following winter, 2012-13, AO flipped into a strong negative phase and the ice growth rate became higher (Fig. 2b). The difference of ice growth rate between the winters of 2011-12 and 2012-13 (Fig. 2c) suggests that the ice growth was substantially suppressed over the
Russian sector of the Arctic in the winter of 2011-12 relative to the winter of 2012-13. The mechanism for this suppression is discussed in detail in section 4 .

Laxon et al. (2013) demonstrated that PIOMAS overpredicts the total Arctic winter ice growth rate measured by CryoSat 2 by around $40 \%$. However, the spatial patterns of the PIOMAS-simulated winter ice growth rates (Figs. 2d,e) are similar to those measured by CryoSat-2 (Figs. 2a,b), although the growth rate is substantially higher than that of CryoSat-2 over the Chukchi and Beaufort Seas. The difference in ice growth between the winters of 2011-12 and 2012-13 shows a clear suppression of ice growth particularly over the Russian sector of the Arctic in the winter of 2011-12

TABLE 1. The 36-yr interannual correlation (from 1980 to 2015) and the last 24-yr correlation (from 1992 to 2015) between the winter AO and September sea ice extent. Dependence of these interannual correlation coefficients to the methods of removing the decadal trend of September sea ice extent is shown.

\begin{tabular}{lcc}
\hline \multirow{2}{*}{$\begin{array}{l}\text { Methods of removing the decadal } \\
\text { trend of September sea ice extent }\end{array}$} & Interannual correlation between winter AO and September sea ice extent \\
\cline { 2 - 3 } 10-yr running average & $1980-2015(36 \mathrm{yr})$ & $1992-2015(24 \mathrm{yr})$ \\
20-yr running average & -0.48 & -0.61 \\
Least squares linear regression & -0.47 & -0.60 \\
\end{tabular}


(a)

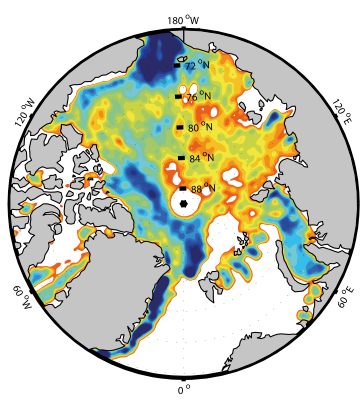

2011-12 winter (b)

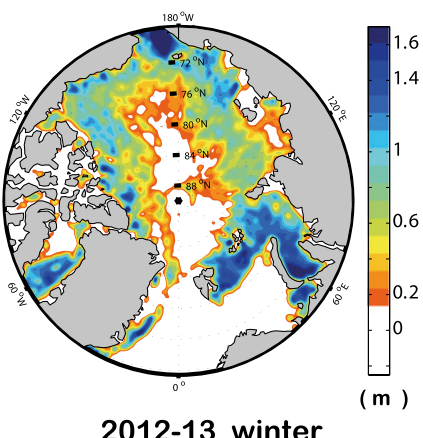

2012-13 winter (c)

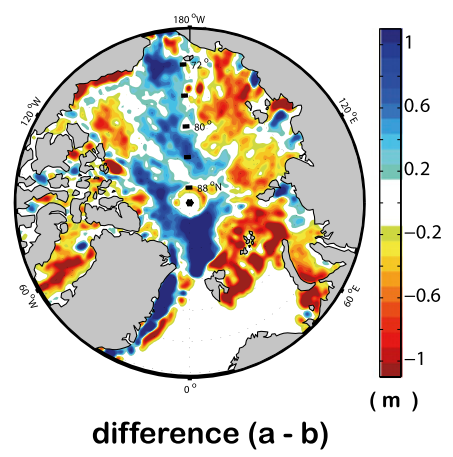

(f)

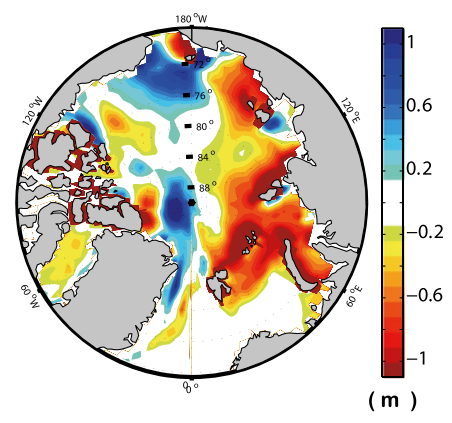

difference $(d-e)$ (d)

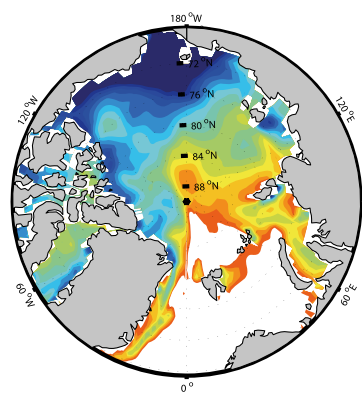

2011-12 winter (e)

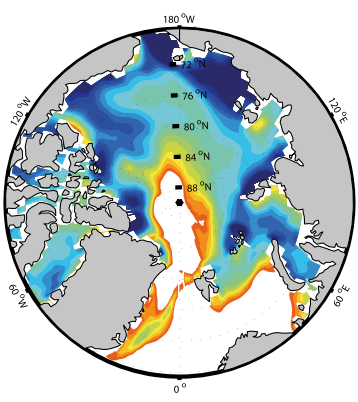

2012-13 winter

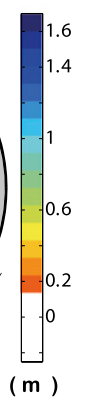

$(\mathrm{m})$

FIG. 2. The wintertime (DJFM) ice thickness growth (unit: $m$ ) during the winters of (a),(d) 2011-12 and (b),(e) 2012-13. (c),(f) The differences of ice growth (unit: $m$ ) between the winters of 2011-12 and 201213 ("2011-12" minus "2012-13") are shown. Measurements from (a)-(c) CryoSat-2 and (d)(f) PIOMAS.

(Fig. 2f), consistent with the observed ice thickness pattern of CryoSat-2 (Fig. 2c). This similarity suggests that PIOMAS may capture the essential physics of sea ice associated with the winter AO events. The spatial correlations (i.e., grid-by-grid correlation) between CryoSat-2 and PIOMAS are 0.33 for the 2011-12 winter (Figs. 2a,c), 0.51 for the 2012-13 winter (Figs. 2b,d), and 0.48 for the difference (Figs. $2 \mathrm{c}, \mathrm{f}$ ) at $1.0^{\circ} \times 1.0^{\circ}$ grid resolution. While these correlation coefficients are significant at the $99 \%$ confidence level, the PIOMAS-simulated sea ice thickness seems to exhibit systematic errors, especially on a regional scale. The same plot for another sea ice reanalysis product, ORAP-5, is presented in the online supplementary materials (Fig. S1). ORAP-5 also exhibits suppression of winter ice growth over the Barents-KaraLaptev Seas in winter of 2011-12 relative to the winter of 2012-13. However, the suppression of ice growth over the East Siberian Sea, the critical region for the summer sea ice extent, is not reproduced. The spatial correlations between CryoSat-2 and ORAP-5 are also generally lower than those between CryoSat-2 and PIOMAS.

\section{Winter AO-induced ice thinning}

The observed ice thickness patterns during the winters of 2011-12 and 2012-13 suggest that a positive (negative) AO event can suppress (enhance) the growth of sea ice. To identify the characteristic pattern of sea ice thickness response to winter $\mathrm{AO}$ events, we now examine the average effects of multiple winter AO events. In particular, we examine the effects of winter AO events on ice thickness change throughout the winter (DJFM) by accounting for all of the positive AO events shown in Fig. 1a.

\section{a. Dynamic effect: Wind-induced ice thinning}

Consistent with Ogi et al. (2016), a broad region of low surface pressure develops during the positive AO winters (Fig. 3a). Large-scale anomalous cyclonic motion occurs around the surface low, causing anomalous southwesterlies over Chukchi-Beaufort Seas as well as the Eurasian Seas. The PIOMAS-simulated ice drift pattern is consistent with the surface wind pattern 
(a) sea level pressure \& surface winds

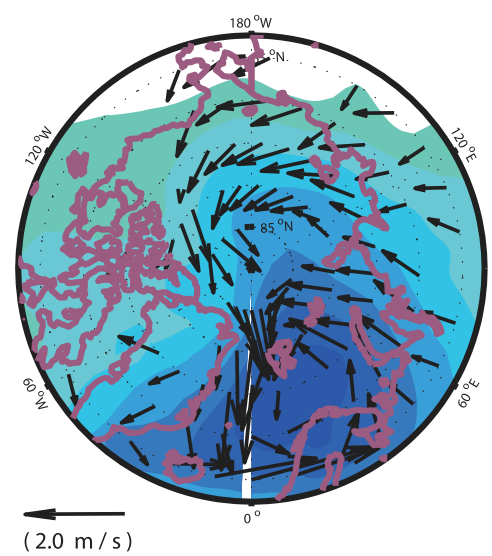

(c) sea ice thickness change

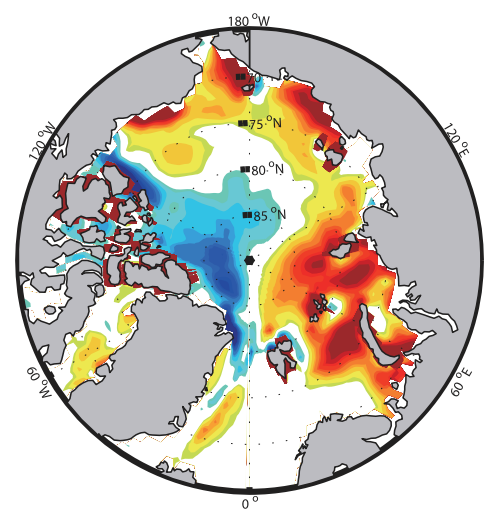

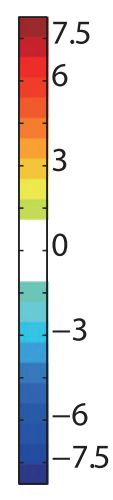

( hPa )

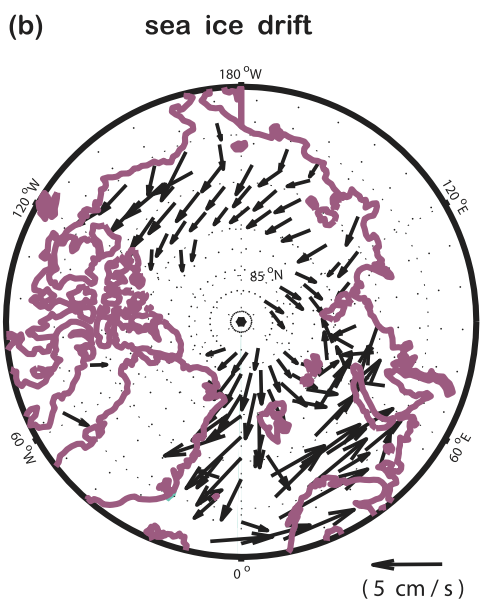

(d) thickness change by ice drift

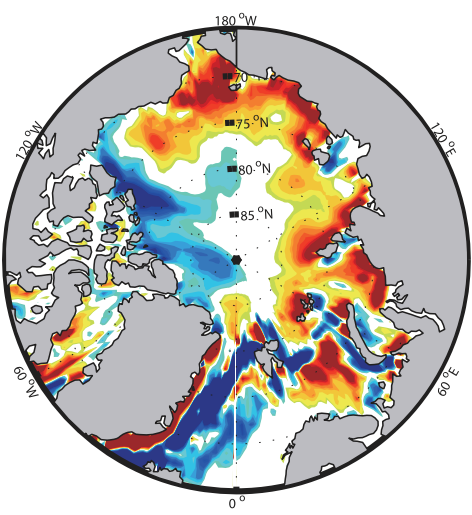

FIG. 3. The anomalous (a) sea level pressure (shadings: Pa) with 10-m winds (vectors: winds stronger than $0.1 \mathrm{~m} \mathrm{~s}^{-1}$ are plotted), (b) ice drift velocity (vectors: ice speeds faster than $0.4 \mathrm{~cm} \mathrm{~s}^{-1}$ are plotted), (c) total sea ice thickness change (cm), and (d) sea ice thickness change $(\mathrm{cm})$ associated with ice drift during positive AO winters (DJFM). The sea level pressure and $10-\mathrm{m}$ winds are from NNR1. Sea ice thickness and velocity are from PIOMAS.

(Fig. 3b). The anomalous ice motion is generally northeastward over wide areas of the Arctic, including the Eurasian coasts and the Pacific sector of the Arctic. The southward drift of sea ice through the Fram Strait increases, which accelerates sea ice mass transport out of Arctic Ocean. These circulation changes are accompanied by sea ice thickness changes. To estimate the sea ice thickness $(h)$ changes during these years, the PIOMASsimulated ice thickness change anomaly, $(d h / d t)^{\prime}$, a deviation from the climatological mean thickness change rate, is calculated and integrated over 4 months (DJFM): $\Delta h^{\prime}=(d h / d t)^{\prime} \Delta t$. The resulting $\Delta h^{\prime}$ indicates that the positive $\mathrm{AO}$ winters experience sea ice thickness changes, around $10-20 \mathrm{~cm}$ thinner than average over wide areas of the Arctic (Fig. 3c). The ice thinning is more pronounced over the European sector of the Arctic (the Barents-Kara Seas) than the Pacific sector of the Arctic (the East Siberian-Chukchi Seas).
This result supports the conjecture of Rigor et al. (2002) and Williams et al. (2016) that the positive winter AO can cause thinning of sea ice over the Pacific sector of the Arctic. Following Park and Stewart (2016), sea ice thickness change associated with ice drift $(u, v)$ can be estimated using the ice flux divergence: $\partial h / \partial t=-[\partial / \partial x(u h)+\partial / \partial y(v h)]$. On interannual and shorter time scales, ice drift is largely wind driven, although the mean geostrophic ocean currents play a nontrivial role on the ice drift velocity (Thorndike and Colony 1982; Leppäranta 2005). Figure 3d verifies that the development of anomalous southwesterlies causes ice flux divergence over the Pacific sector of the Arctic as well as the Eurasian Seas, decreasing sea ice thickness regionally by up to $20-25 \mathrm{~cm}$. The correspondence between the thickness anomalies shown in Figs. $3 \mathrm{c}$ and $3 \mathrm{~d}$ indicates that the ice flux divergence is a key factor for sea ice thinning during the positive $\mathrm{AO}$ winters. 
(a) IABP: sea ice drift

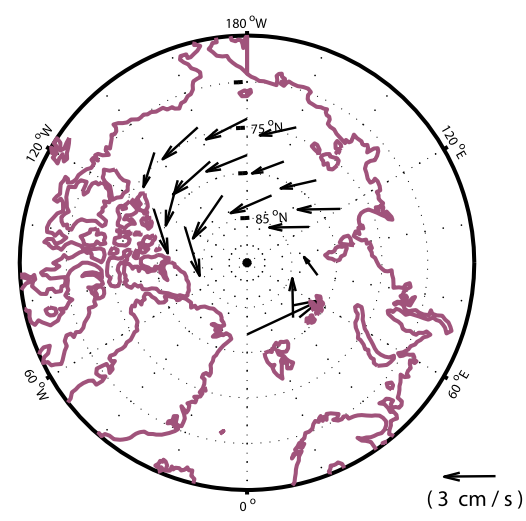

IABP vs. PIOAS: Interannual correlation of zonal ice

(b)

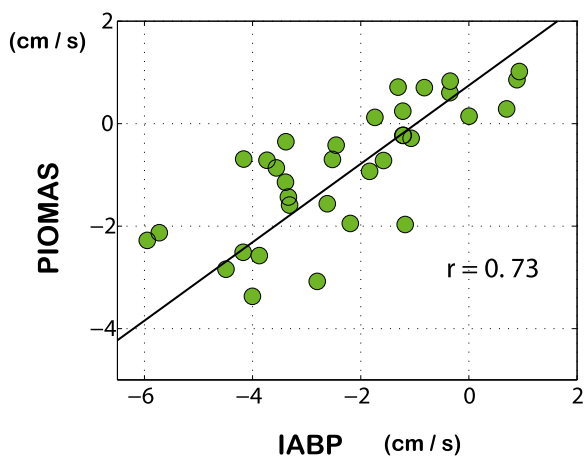

(c) East Siberian - Chukchiu Seas

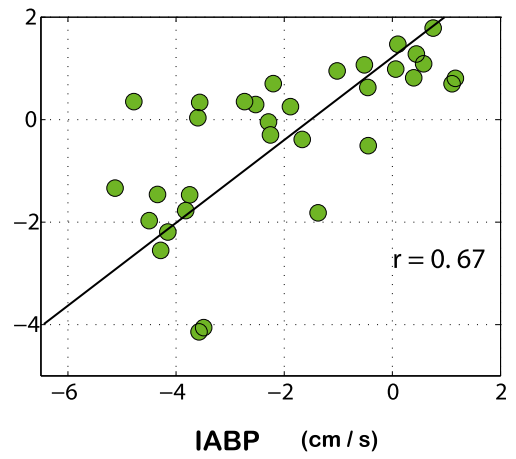

FIG. 4. (a) Ice drift velocity (vectors: ice speeds faster than $0.6 \mathrm{~cm} \mathrm{~s}^{-1}$ are plotted) from the interpolated IABP during positive AO winters (as in Fig. 2b, but that the data source is different). The wintertime (DJFM mean) interannual correlation of zonal ice drift velocity between the IABP and PIOMAS averaged over (b) the Beaufort Sea $\left(69^{\circ}-79^{\circ} \mathrm{N}, 200^{\circ}-240^{\circ} \mathrm{E}\right)$ and (c) the East Siberian-Chukchi Seas $\left(69^{\circ}-79^{\circ} \mathrm{N}, 140^{\circ}-200^{\circ} \mathrm{E}\right)$.

Another sea ice reanalysis product, ORAP-5, also simulates the anticyclonic ice drift during the positive AO winters (Fig. S1). The winter ice thickness change anomaly, $(d h / d t)^{\prime}$ is generally negative (i.e., growing less ice in positive AO winters), but this thinning is largely confined over the Barents-Kara Seas. The suppression of ice growth over the East Siberian Sea, which appears clearly in PIOMAS, is not simulated by ORAP-5.

As the wind-induced ice drift simulated by PIOMAS is forced by a reanalysis wind field, we now use IABP ice drift data to validate the PIOMAS-simulated ice drift velocity (Fig. 4). The ice drift from the interpolated IABP shows anomalous eastward drift during positive AO winters (Fig. 4a), which is generally consistent with the PIOMAS ice drift pattern. Figures $4 b, c$ further shows that the interannual correlation between the IABP and PIOMAS zonal ice velocity is around 0.7 both over the Beaufort Sea and the East Siberian-Chukchi Seas. These results suggest that the PIOMAS-simulated ice velocity is generally consistent with observations on interannual time scales. However, the observed (IABP) interannual variations of zonal ice drift velocity range from -6 to $1 \mathrm{~cm} \mathrm{~s}^{-1}$ (up to $7 \mathrm{~cm} \mathrm{~s}^{-1}$ difference), whereas those of PIOMAS range from -3.5 to $1 \mathrm{~cm} \mathrm{~s}^{-1}$ (up to $4.5 \mathrm{~cm} \mathrm{~s}^{-1}$ difference) in the Beaufort Sea (Fig. 4b). The East Siberian-Chukchi Seas also exhibit that smaller interannual variation in the ice drift in PIOMAS than in IABP (Fig. 4c). Compared to the observational record, PIOMAS underestimates the interannual variation of zonal ice drift speed by $30 \%-40 \%$. This is consistent with a study that reported the climate model-simulated ice drift speed to be substantially slower than the IABPmeasured ice drift speed (Rampal et al. 2011). Therefore, the positive AO-induced ice thinning simulated by PIOMAS (Fig. 3d) is likely to be an underestimate. 


\section{b. Thermodynamic forcing: Suppressed heat loss}

While the effect of winter AO on ice drift has previously been examined (Rigor et al. 2002; Williams et al. 2016), thermodynamically driven thinning has received relatively little attention in this context. Recent studies indicate that thermodynamic forcing has played an important role in winter ice thinning/thickening in recent years (Liu and Key 2014; Park et al. 2015; Cullather et al. 2016; Kim et al. 2017). Assuming a steady state (i.e., that the ice rapidly equilibrates to the heat fluxes at the base and at the top of the ice), the heat balance at the ice-atmosphere interface can be simplified as (Thorndike 1992)

$F_{c}^{\uparrow}=F_{\mathrm{SW}}{ }^{\uparrow}-F_{\mathrm{SW}}{ }^{\downarrow}+F_{\mathrm{LW}}{ }^{\uparrow}-F_{\mathrm{LW}^{\downarrow}}+\mathrm{SHF}^{\uparrow}+\mathrm{LHF}^{\uparrow}$,

where $F_{c}^{\uparrow}$ is conductive heat flux through the snowcovered sea ice; $F_{\mathrm{LW}}^{\uparrow}$ and $F_{\mathrm{LW}}{ }^{\downarrow}$ are upward and downward longwave radiative fluxes, respectively; and $\mathrm{SHF}^{\uparrow}$ and $\mathrm{LHF}^{\uparrow}$ denote sensible and latent heat fluxes, respectively. Here, shortwave radiation at the surface $\left(F_{\mathrm{SW}}{ }^{\downarrow}, F_{\mathrm{SW}}{ }^{\uparrow}\right)$, which is much weaker than other heat fluxes in winter, can be neglected. Equation (1) can be converted to ice growth rate, $d h / d t$ :

$$
\frac{d h}{d t}=F_{c}^{\uparrow} / q
$$

where $q$ is the amount of energy needed to melt a unit volume of sea ice. The ocean surface temperature contacting sea ice is typically very near freezing temperature $(T \approx-1.8 \mathrm{~K})$ and the representative salinity near the base of multiyear sea ice is about $\mathrm{S}=32 \%$ (Weeks and Ackley 1986). For these typical values of $\mathrm{T}$ and $\mathrm{S}$, $q \approx 0.9 \rho_{i} L_{f}$ (Bitz and Lipscomb 1999), where $\rho_{i}$ is the density of ice and $L_{f}$ is the latent heat of fusion. More generally, the ice growth rate is obtained by adding the ocean-to-ice heat flux $\left(F_{\mathrm{OI}}^{\uparrow}\right)$ at the base of sea ice:

$$
\frac{d h}{d t}=\left(F_{c}^{\uparrow}-F_{\mathrm{OI}}^{\uparrow}\right) / q .
$$

When the sea surface is at or very close to the freezing point $(T \approx-1.8 \mathrm{~K}), F_{\mathrm{OI}}{ }^{\uparrow}$ vanishes and the surface heat flux anomalies $\left(F_{\mathrm{LW}}{ }^{\uparrow}-F_{\mathrm{LW}}{ }^{\downarrow}+\mathrm{SHF}^{\uparrow}+\mathrm{LHF}^{\uparrow}\right)$ in winter can accelerate or suppress be the ice growth rate $(d h / d t)$.

Figure 5 presents net surface heat flux $\left(F_{\mathrm{LW}^{\uparrow}}-F_{\mathrm{LW}^{\downarrow}}+\mathrm{SHF}^{\uparrow}+\mathrm{LHF}^{\uparrow}\right)$ anomalies during the positive AO winters simulated by NNR (Fig. 5a), ERAI (Fig. 5b), and MERRA (Fig. 5c). In NNR, the heat flux anomalies in winter (DJFM) are generally small, except for the Kara and the northern Barents Seas, where anomalous downward heat flux may have contributed to suppressing the winter ice growth. However, these downward surface heat flux anomalies are compensated by downward (i.e., reduced) ocean-to-ice heat flux anomalies (blue colors in Fig. 5d), indicating that downward surface heat flux anomalies do not directly translate to negative ice growth anomalies. In ERAI, the heat flux anomalies are much larger, about $1-2 \mathrm{~W} \mathrm{~m}^{-2}$ downward over wide areas of Arctic Ocean, except for the western Barents and Greenland Seas, where SIC is anomalously low (Fig. 5e). The suppressed heat loss over the ice surface is mainly due to suppressed surface sensible heat flux $\left(\mathrm{SHF}^{\uparrow}\right)$ associated with the weaker surface wind speed, and due to increased downward longwave radiation $\left(F_{\mathrm{LW}}{ }^{\downarrow}\right)$ that is sensitive to southerly induced heat/moisture transport (Woods et al. 2013; Park et al. 2015). In winter, surface temperatures at the bottom of sea ice are mostly lower than $-1.75^{\circ} \mathrm{C}$ in the central Arctic, except the western Barents and Greenland Seas (Fig. S2). So, the anomalous downward heat fluxes (i.e., suppressed surface heat loss) should translate to anomalously small freezing rates, though this cannot be directly tested because of the absence of an active ocean component in ERAI. Equation (2a) indicates that decreasing surface heat fluxes around $1-1.5 \mathrm{~W} \mathrm{~m}^{-2}$, suppresses the growth of sea ice by $3.0-4.5 \mathrm{~cm}$ over the winter (DJFM). This thermodynamic thinning associated with positive AO winters therefore contributes a modest addition to the dynamic thinning diagnosed in section 3a. The heat flux anomalies are also downward in MERRA (Fig. 5c), although these downward heat flux anomalies are smaller than those of ERAI.

As shown in Eq. (2b), the ocean-to-ice heat flux $\left(F_{\text {OI }}{ }^{\uparrow}\right)$ can influence the growth and melting of winter sea ice. Recent studies have shown that decadal variations in North Atlantic Oscillation can affect the ocean heat transport into the Arctic, causing substantial changes in Arctic sea ice cover (Miles et al. 2014; Delworth et al. 2016). On interannual time scales, ocean heat flux convergence over the western Barents Sea is well correlated with sea ice concentration in the winter (Årthun et al. 2012). PIOMAS simulations confirm that the ocean heat flux-induced ice melting anomalies during positive $\mathrm{AO}$ winters can decrease sea ice thickness by $20-30 \mathrm{~cm}$ over the Barents Sea (Fig. 5d), explaining the anomalous upward heat fluxes in these regions (Figs. 5a-c). Except for the Barents Sea, the ocean-to-ice heat flux anomalies are generally downward along the coasts of the Kara Sea and the Beaufort Sea (blue colors in Fig. 5d), compensating for the downward surface heat flux anomalies in NNR (red colors in Fig. 5a). In ERAI and MERR, the anomalous downward surface heat fluxes occur in the central Arctic (Figs. 5b,c), where the ocean-to-ice heat flux anomalies are almost zero in PIOMAS, and so these surface heat flux anomalies in the central Arctic should 
(a) NCEP: surface heat flux

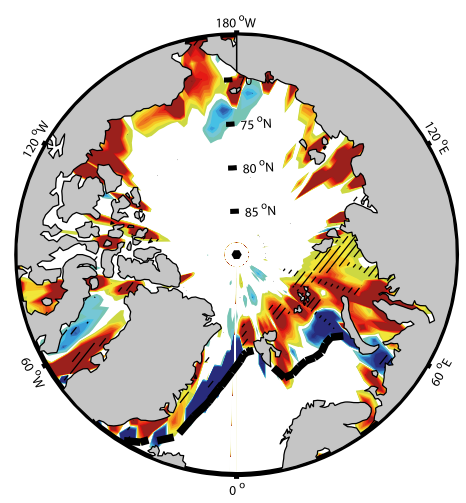

(b) ERAl: surface heat flux

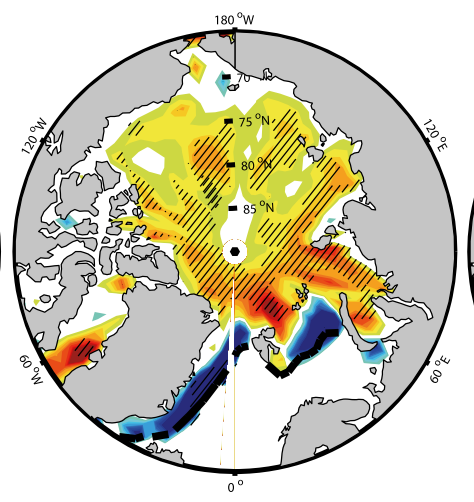

(c) MERRA: surface heat flux

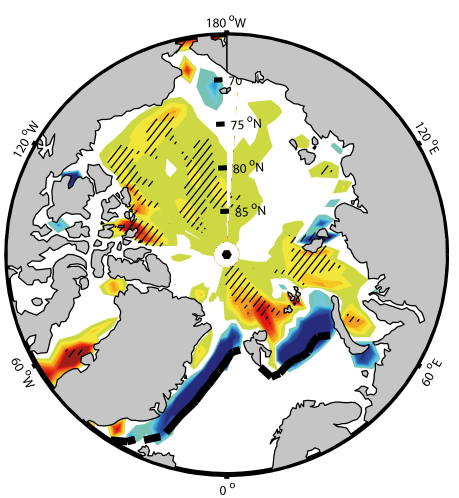

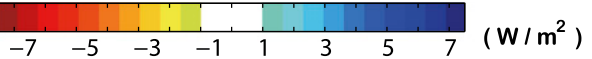

(d)

PIOMAS: Ice thickness change by ocean heat flux

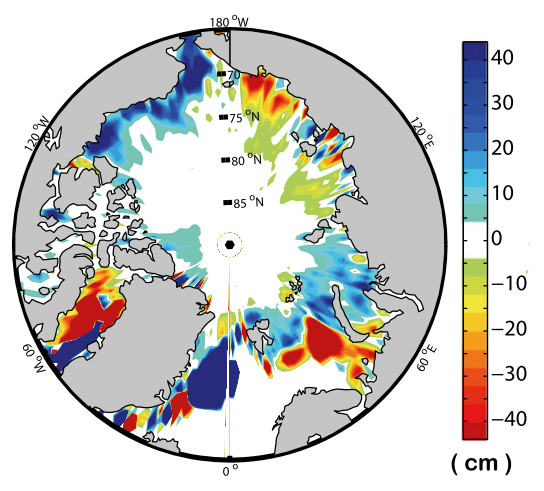

(e) NSIDC: sea ice concent

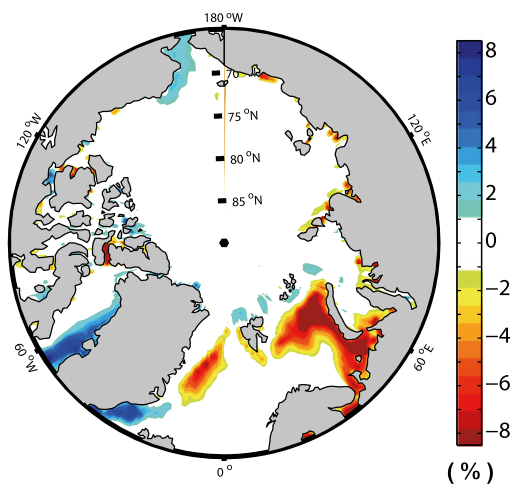

FIG. 5. The anomalous net surface heat flux $\left(F_{\mathrm{SW}}{ }^{\uparrow}-F_{\mathrm{SW}}{ }^{\downarrow}+F_{\mathrm{LW}}{ }^{\uparrow}-F_{\mathrm{LW}}{ }^{\downarrow}+\mathrm{SHF}^{\uparrow}+\mathrm{LHF}^{\uparrow} ; \mathrm{W} \mathrm{m}^{-2}\right)$ diagnosed from (a) NNR, (b) ERAI, and (c) MERRA, averaged during the positive AO winters (DJFM). (d) Ocean heat fluxinduced ice thickness anomalies $(\mathrm{cm})$ from PIOMAS integrated throughout the winter (DJFM) and (e) the anomalous winter SIC. In (a)-(c), statistically significant values $(p<0.05)$ are hatched.

translate to anomalous ice thinning (i.e., suppression of ice growth).

\section{Radiative response in late spring and summer}

In this section we show that the winter AO-induced ice thinning preconditions the Pacific sector of the Arctic for an enhanced ice-albedo feedback in the following summer. The ice volume anomalies in MarchApril following the positive winter AO are small both in the Eurasian $\left(0^{\circ}-140^{\circ} \mathrm{E}\right.$; Barents-Kara-Laptev Seas; Fig. 6a) and the Pacific sector of the Arctic $\left(140^{\circ}-230^{\circ} \mathrm{E}\right.$; East Siberian-Chukchi-Beaufort Seas; Fig. 6b). In the Eurasian sector, the ice volume in March-April is about $300-350 \mathrm{~km}^{3}$ smaller than the average, far exceeding the intrinsic variability (gray shadings in Fig. 6a). Interestingly, in late spring-summer, there is a recovery of the ice volume and area in the Eurasian sector (Figs. 6a,c), whereas they exhibit a continuing decline in the Pacific sector (Figs. 6b,d). This is partly due to ice flux convergence (divergence) anomalies over the Eurasian (Pacific) sector of the Arctic in spring and summer (Fig. 6f). The climatological-mean westward drift of sea ice from the Pacific sector to the Eurasian sector may contribute to this recovery (decline) of the ice volume over the Eurasian (Pacific) sector. In the Pacific sector, the continuous decline of ice volume is accompanied by a rapid decline of sea ice area in summer, especially in July (Fig. 6d), during which shortwave radiation is strong and the ice-albedo feedback is effective (Eisenman et al. 2007). In Fig. 6g we plot the difference between the total ice thickness change (Fig. 6e) and the ice drift-induced thickness change (Fig. 6f) to quantify the role of lagged thermal forcing. This shows that both the mechanical forcing and the lagged thermal forcing substantially contribute to the anomalous 


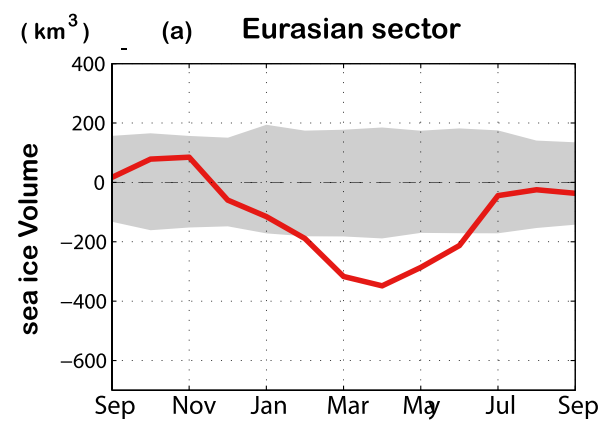

\section{(b) Pacific sector}
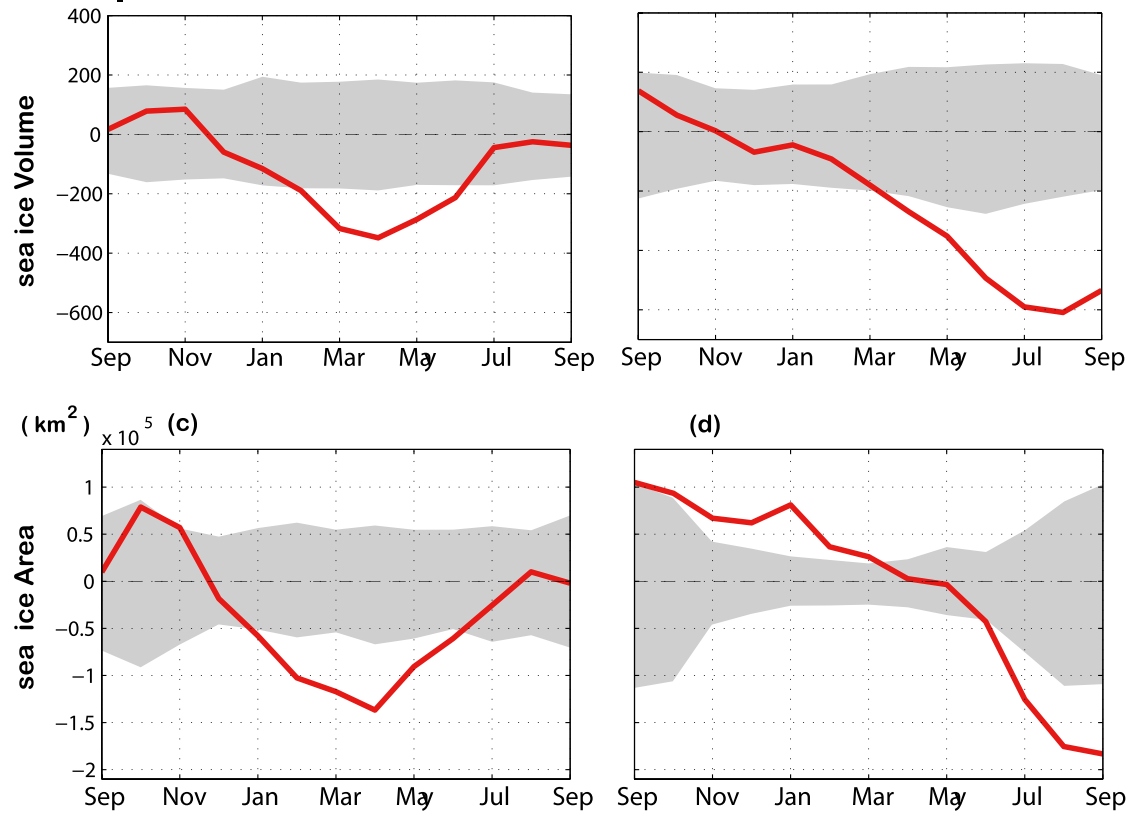

(d)

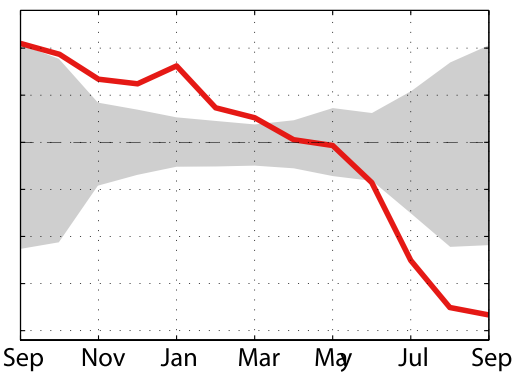

Apr-May-Jun-Jul-Aug

(e) total thickness change

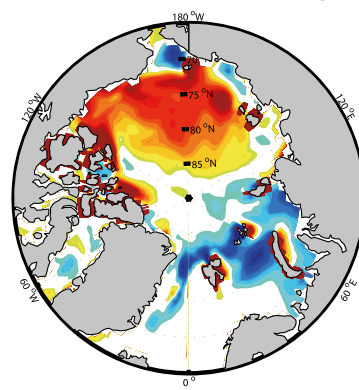

(f) ice drift effect

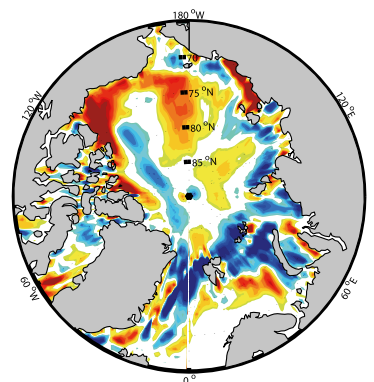

(g) thermal effect: $(e-f)$

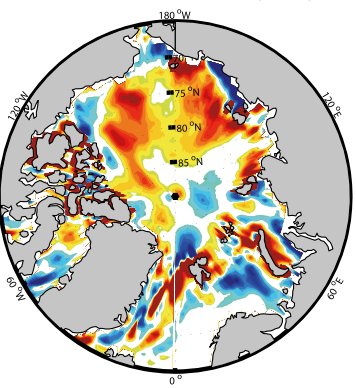

$(\mathrm{cm})$

FIG. 6. Composite time evolution of anomalous (a),(b) sea ice volume and (c),(d) sea ice area for the years of positive winter AO (from the preceding September to the following September), averaged over the (a), (c) Eurasian sector $\left(0^{\circ}-140^{\circ} \mathrm{E}\right)$ and the (b), (d) Pacific sector $\left(140^{\circ}-230^{\circ} \mathrm{E}\right)$ of the Arctic. The gray shadings indicate $95 \%$ confidence interval range of values in sea ice volume and area anomalies. (e) Total sea ice thickness change (cm), (f) sea ice thickness change associated with ice drift, and (g) sea ice thickness change associated with thermodynamic forcing in spring-summer (April-May-June-July-August) following positive $\mathrm{AO}$ winters. The sea ice volume (thickness) data in (a),(b),(e),(f),(g) area from PIOMAS and the sea ice area data in (c),(d) are from NSIDC.

spring-summer ice thinning following positive $\mathrm{AO}$ winters.

Reanalysis data verify that the spring-summer net surface radiative response to the winter $\mathrm{AO}$ is statistically significant at the $95 \%$ level (Figs. 7a, 8a, and 9a); the interannual correlation between the winter $\mathrm{AO}$ and subsequent spring-summer (averaged from April to August) net surface radiation averaged over the Pacific sector of the Arctic $\left(69^{\circ}-77^{\circ} \mathrm{N}, 140^{\circ}-230^{\circ} \mathrm{E}\right)$ is -0.43 in NNR, -0.36 in ERAI, and -0.38 in MERRA. Here, the net surface radiation implies the sum of net shortwave $\left(\mathrm{SW}^{\uparrow}-\mathrm{SW}^{\downarrow}\right)$ and net longwave $\left(\mathrm{LW}^{\uparrow}-\mathrm{LW}^{\downarrow}\right)$ radiation at the surface. The seasonal evolution of net surface radiation shows that the anomalously downward (absorbed into surface) net shortwave radiation $\left(\mathrm{SW}^{\uparrow}-\mathrm{SW}^{\downarrow}\right)$ rapidly increases from spring to early 
(a) interannual correlation

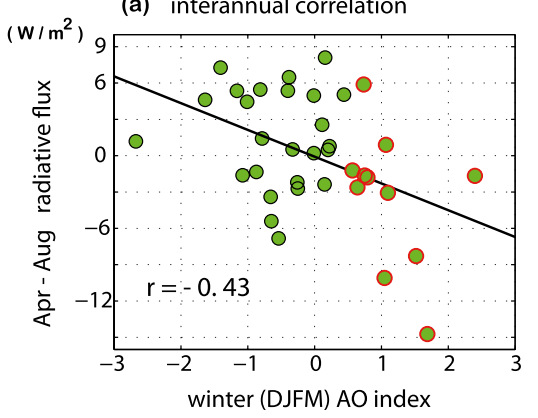

(b) composite seasonal evolution

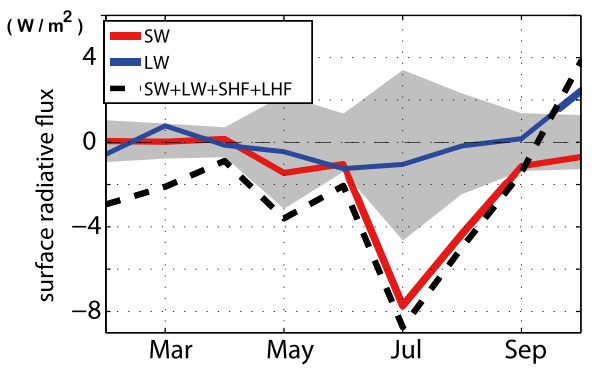

surface radiative flux $(\mathrm{SW}+\mathrm{LW})$
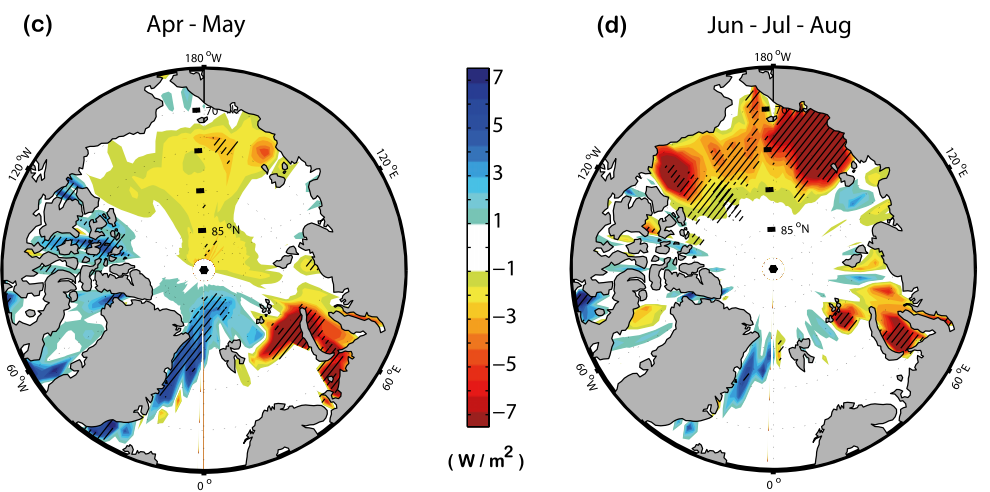

FIG. 7. The interannual correlation (a) between the wintertime (DJFM) mean AO index and anomalous net surface radiation $\left(F_{\mathrm{SW}}{ }^{\uparrow}-F_{\mathrm{SW}}{ }^{\downarrow}+F_{\mathrm{LW}}{ }^{\uparrow}-F_{\mathrm{LW}}{ }^{\downarrow} ; \mathrm{W} \mathrm{m}^{-2}\right)$ in spring-summer (averaged from April to August), averaged over the Pacific sector of the Arctic $\left(69^{\circ}-77^{\circ} \mathrm{N}\right.$, $140^{\circ}-230^{\circ} \mathrm{E}$ ). (b) Composite time evolution of anomalous net shortwave radiation (red line; $F_{\mathrm{SW}}{ }^{\uparrow}-F_{\mathrm{SW}}{ }^{\downarrow}$ ), longwave radiation (blue line; $F_{\mathrm{LW}}{ }^{\uparrow}-F_{\mathrm{LW}}{ }^{\downarrow}$ ), and net heat fluxes (black dotted line; $\left.F_{\mathrm{SW}}{ }^{\uparrow}-F_{\mathrm{SW}}{ }^{\downarrow}+F_{\mathrm{LW}} \uparrow-F_{\mathrm{LW}^{\downarrow}}+\mathrm{SHF}^{\uparrow}+\mathrm{LHF}^{\uparrow}\right)$ at the surface over the Pacific sector of the Arctic $\left(69^{\circ}-77^{\circ} \mathrm{N}, 140^{\circ}-230^{\circ} \mathrm{E}\right)$ following the positive $\mathrm{AO}$ winters. The gray shading indicates a $95 \%$ confidence interval range of values in net surface radiation anomalies. Composite of net surface radiation $\left(\mathrm{W} \mathrm{m}^{-2}\right)$ in (c) spring (April-May) and (d) summer (June-July-August) following the positive AO winters. In (c), (d), warm colors imply anomalously large radiative fluxes absorbed at the surface, and statistically significant values $(p<0.05)$ are hatched. In (a), green dots with red circles indicate the anomalously positive AO winters. Surface radiative flux data are from NNR.

summer, peaking in July following the positive winter AO (red line in Fig. 7b). Figure $7 d$ shows that the downward net radiation anomalies are particularly large over the East Siberian and Beaufort Seas, where the AO-induced ice thinning in winter is largest. These results support the hypothesis that a thinner sea ice can induce a more rapid ice-albedo feedback in late springearly summer, causing summer enhancement of ice thickness anomalies (Bushuk et al. 2017). The longwave radiative anomalies $\left(\mathrm{LW}^{\uparrow}-\mathrm{LW}^{\downarrow}\right.$; blue line in Fig. $7 \mathrm{~b}$ ) are generally small, indicating that the net shortwave radiation response (ice-albedo feedback) is a major factor causing the summer enhancement of ice thickness anomalies. The composites of net heat fluxes, including the surface latent and sensible heat fluxes $\left(\mathrm{SW}^{\uparrow}-\mathrm{SW}^{\downarrow}+\mathrm{LW}^{\uparrow}-\mathrm{LW}^{\downarrow}+\mathrm{LHF}^{\uparrow}+\mathrm{SHF}^{\uparrow}\right)$, consistently show anomalously downward heat fluxes in the late spring and summer (black dotted line in Fig. 7b). In spring and summer (from April to August), net heat flux anomalies are about $3-4 \mathrm{~W} \mathrm{~m}^{-2}$ downward over the Pacific sector of the Arctic. Calculation from Eqs. (1) and (2a) indicates that decreasing the net surface heat fluxes by $2-3 \mathrm{~W} \mathrm{~m}^{-2}$ can decrease ice thickness by $8-10 \mathrm{~cm}$ over a 5 -month period (from April to August), assuming that the ocean surface temperature contacting sea ice is typically very near freezing temperature $\left(q \approx 0.9 \rho_{i} L_{f}\right)$. This is comparable to the spring-summer ice thinning following the anomalously strong longwave radiative forcing in the spring (Kapsch et al. 2013).

The results shown in Fig. 7 are qualitatively reproduced using other reanalysis data: ERAI and MERRA (Figs. 8 and 9). Consistent with NNR, the interannual correlation between the winter $\mathrm{AO}$ and subsequent spring-summer net surface radiation are about -0.36 
(a) interannual correlation

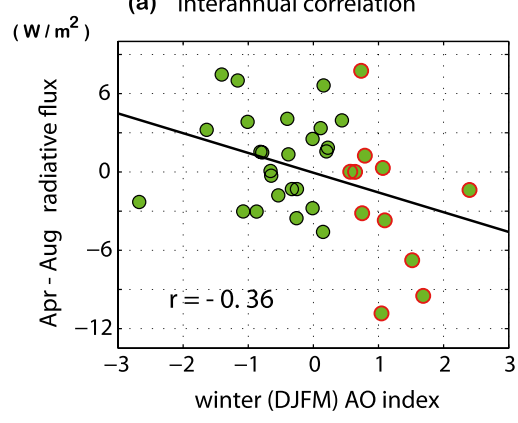

(b) composite seasonal evolution

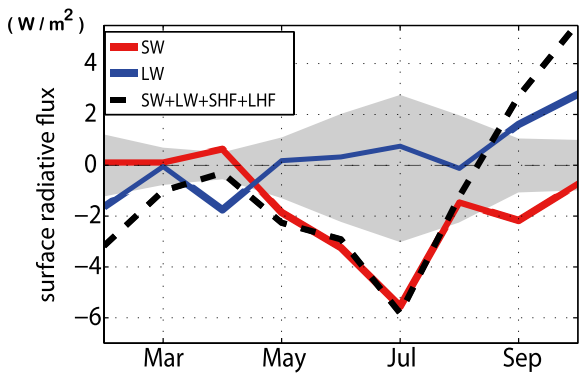

surface radiative flux $(S W+L W)$
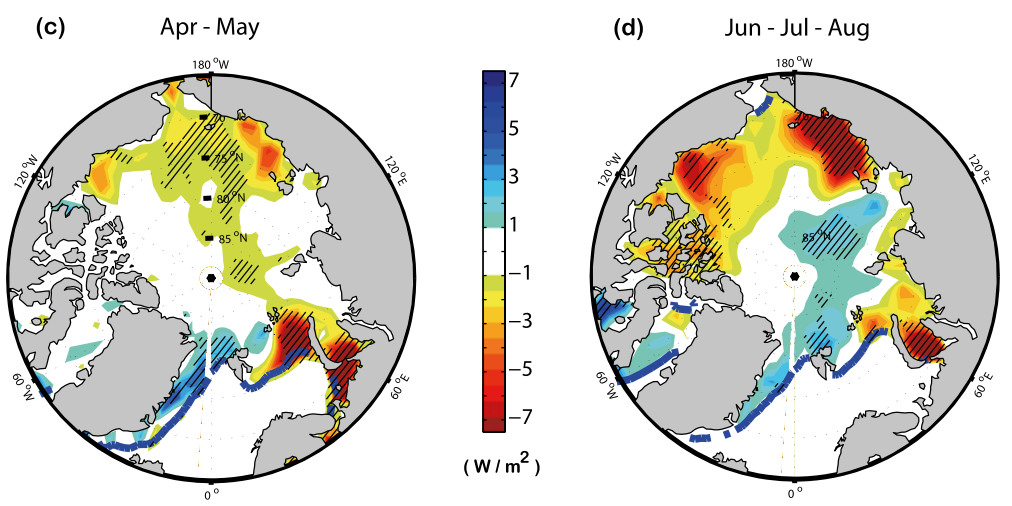

FIG. 8. As in Fig. 7, but for ERAI.

and -0.38 , which are statistically significant (Figs. 8a, 9a). All three reanalysis data show that net shortwave radiation is a leading factor causing downward heat flux anomalies in the late spring and summer following the positive winter AO (red lines in Figs. 7b, 8b, and 9b), verifying that the winter $\mathrm{AO}$-induced ice thinning can cause summer enhancement of ice thickness anomalies via the ice-albedo feedback. In NNR and MERRA, the downward net radiation anomalies in the summer (JuneJuly-August) are more pronounced (Figs. 7d, 9d) than that of ERAI (Fig. 8d). Unlike NNR and ERAI, sensible and latent heat flux anomalies in MERRA are significantly downward in spring and early summer, further contributing to the ice melting (black dotted line in Fig. 8b).

\section{Summary and discussion}

This study provides a detailed mechanistic connection between the winter $\mathrm{AO}$ and summer sea ice extent. Throughout the winter, the positive AO-induced ice drift decreases sea ice thickness by 15 and $10 \mathrm{~cm}$ over the Eurasian and the Pacific sectors of the Arctic, respectively. This dynamic thinning may be accompanied by a weaker thermodynamic suppression of ice growth due to reduced upward sensible heat flux and enhanced downward longwave heat flux, though the reanalyses products examined here disagree on the spatial distribution and magnitude of this effect. In the Pacific sector of the Arctic, the positive winter AO-induced ice volume and area anomalies amplify in the subsequent late spring and summer, primarily because of ice-albedo feedback. Our calculation suggests that the springsummer thermodynamic forcing can further decrease ice thickness by around $10 \mathrm{~cm}$ in the Pacific sector of the Arctic.

One of limitations of this study is that we present the average effects of 11 positive $\mathrm{AO}$ winters using reanalysis products, rather than using direct observational estimates. Because the record of satellite-observed sea ice thickness is short, observational assessment of the winter AO-induced ice thickness changes is only possible over the last several years. PIOMAS data show that the wind-induced ice flux divergence causes the ice thinning over the Eurasian Seas and the Pacific sector of the Arctic in the case when all the 11 winters are averaged (Fig. 3). However, as shown in the difference of ice growth between the winters of 2011-12 and 2012-13 (Figs. 2c,f), the individual AO may exhibit widely different ice thickness patterns over Arctic Ocean. Between individual winters, a positive winter AO sometimes has little influence on the Pacific sector of the Arctic (not shown), the critical area for the summer sea ice extent. Instead, thermodynamic effects, specifically 
(a) interannual correlation

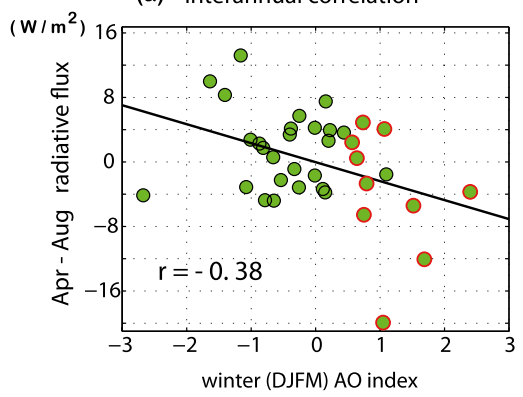

(b) composite seasonal evolution

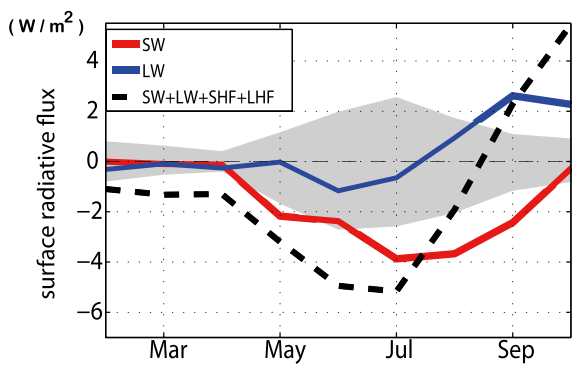

surface radiative flux $(\mathrm{SW}+\mathrm{LW})$
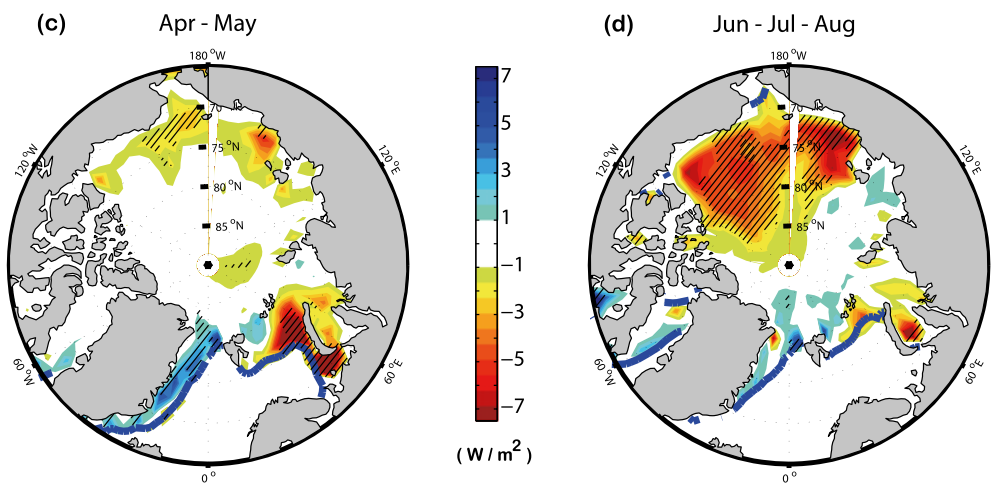

FIG. 9. As in Figs. 7 and 8, but for MERRA.

downward longwave radiation $\left(\mathrm{LW}^{\downarrow}\right)$ played a role in several winters over the last decade; the increase in $\mathrm{LW}^{\downarrow}$ in the positive AO winter of 2011-12 and the increase in $\mathrm{LW}^{\downarrow}$ in the negative AO winter of 2012-13 (Liu and Key 2014) is an example of a thermodynamic impact accompanying the winter $\mathrm{AO}$ variations.

In summary, our analysis suggests that winter atmospheric circulation patterns associated with the AO can substantially change sea ice thickness throughout the winter, preconditioning the ice for an enhanced albedo feedback in summer. This study elucidates new causal links to explain the established correlation between the winter AO index and the September sea ice extent. Thus, we suggest that the winter AO index may be used to better predict interannual variability of summer sea ice extent. Arctic sea ice has been projected to become thinner with future climate change (Holland et al. 2006). Therefore, wintertime variation of Arctic surface winds is likely to be even more influential in changing the seasonal cycle of sea ice volume and the summer sea ice extent in the future.

Acknowledgments. We thank four anonymous reviewers for their constructive and insightful comments. HSP is supported by the Basic Research Project (GP2017-013) of the Korea Institute of Geoscience and Mineral Resource (KIGAM), Ministry of Science, ICT, and Future Planning. ALS is supported by the National Science Foundation under Grant PLR-1543388.

\section{REFERENCES}

Årthun, M., T. Eldevik, L. H. Smedsrud, Ø. Skagseth, and R. B. Ingvaldsen, 2012: Quantifying the influence of Atlantic heat on Barents Sea ice variability and retreat. J. Climate, 25, 4736-4743, https://doi.org/10.1175/JCLI-D-11-00466.1.

Bitz, C. M., and W. H. Lipscomb, 1999: An energy-conserving thermodynamic model of sea ice. J. Geophys. Res., 104, 15 669-15 677, https://doi.org/10.1029/1999JC900100.

Blanchard-Wrigglesworth, E., K. Armou, C. M. Bitz, and E. DeWeaver, 2011: Persistence and inherent predictability of Arctic sea ice in a GCM ensemble and observations. J. Climate, 24, 231-250, https://doi.org/10.1175/ 2010JCLI3775.1.

_ R. I. Cullather, W. Wang, J. Zhang, and C. M. Bitz, 2015: Model forecast skill and sensitivity to initial conditions in the seasonal sea ice outlook: Summer sea ice forecast skill in models. Geophys. Res. Lett., 42, 8042-8048, https://doi.org/ 10.1002/2015GL065860.

Bushuk, M., R. Msadek, M. Winton, G. Vecchi, R. Gudgel, A. Rosati, and X. Yang, 2017: Summer enhancement of Arctic sea ice volume anomalies in the September-ice zone. J. Climate, 30, 2341-2362, https://doi.org/10.1175/ JCLI-D-16-0470.1.

Chevallier, M., and D. Salas-Mélia, 2012: The role of sea ice thickness distribution in the Arctic sea ice potential predictability: A diagnostic approach with a coupled 
GCM. J. Climate, 25, 3025-3038, https://doi.org/10.1175/ JCLI-D-11-00209.1.

Cullather, R. I., Y.-K. Lim, L. N. Boisvert, L. Brucker, J. N. Lee, and S. M. J. Nowicki, 2016: Analysis of the warmest Arctic winter, 2015-2016. Geophys. Res. Lett., 43, 10 808-10816, https://doi.org/10.1002/2016GL071228.

Day, J. J., E. Hawkins, and S. Tietsche, 2014: Will Arctic sea ice thickness initialization improve seasonal forecast skill? Geophys. Res. Lett., 41, 7566-7575, https://doi.org/10.1002/ 2014GL061694.

Dee, D. P., and Coauthors, 2011: The ERA-Interim reanalysis: Configuration and performance of the data assimilation system. Quart. J. Roy. Meteor. Soc., 137, 553-597, https://doi.org/ 10.1002/qj.828.

Delworth, T. L., F. Zeng, G. A. Vecchi, X. Yang, L. Zhang, and R. Zhang, 2016: The North Atlantic Oscillation as a driver of rapid climate change in the Northern Hemisphere. Nat. Geosci., 9, 509-512, https://doi.org/10.1038/ngeo2738.

Döscher, R., T. Vihma, and E. Maksimovich, 2014: Recent advances in understanding the Arctic climate system state and change from a sea ice perspective: A review. Atmos. Chem. Phys., 14, 13 571-13 600, https://doi.org/10.5194/acp-14-135712014.

Eisenman, I., N. Untersteiner, and J. S. Wettlaufer, 2007: On the reliability of simulated Arctic sea ice in global climate models. Geophys. Res. Lett., 34, L10501, https://doi.org/10.1029/ 2007GL029914.

Graversen, R. G., T. Mauritsen, S. Drijfhout, M. Tjernström, and S. Mårtensson, 2011: Warm winds from the Pacific caused extensive Arctic sea-ice melt in summer 2007. Climate Dyn., 36, 2103-2112, https://doi.org/10.1007/s00382-010-0809-z.

Holland, M. M., and J. C. Stroeve, 2011: Changing seasonal sea ice predictor relationships in a changing Arctic climate. Geophys. Res. Lett., 38, L18501, https://doi.org/10.1029/2011GL049303.

_ C. M. Bitz, and B. Tremblay, 2006: Future abrupt reductions in the summer Arctic sea ice. Geophys. Res. Lett., 33, L23503, https://doi.org/10.1029/2006GL028024.

Kalnay, E., and Coauthors, 1996: The NCEP/NCAR 40-Year Reanalysis Project. Bull. Amer. Meteor. Soc., 77, 437-471, https:// doi.org/10.1175/1520-0477(1996)077<0437:TNYRP>2.0.CO;2.

Kapsch, M.-L., R. G. Graversen, and M. Tjernström, 2013: Springtime atmospheric energy transport and the control of Arctic summer sea-ice extent. Nat. Climate Change, 3, 744748, https://doi.org/10.1038/nclimate1884.

Kay, J. E., T. L'Ecuyer, A. Gettelman, G. Stephens, and C. O'Dell, 2008: The contribution of cloud and radiation anomalies to the 2007 Arctic sea ice extent minimum. Geophys. Res. Lett., 35, L08503, https://doi.org/10.1029/2008GL033451.

Kim, B.-M., and Coauthors, 2017: Major cause of unprecedented Arctic warming in January 2016: Critical role of an Atlantic windstorm. Sci. Rep., 7, 40051, https://doi.org/10.1038/srep40051.

Kwok, R., and D. A. Rothrock, 2009: Decline in Arctic sea ice thickness from submarine and ICESat records: 1958-2008. Geophys. Res. Lett., 36, L15501, https://doi.org/10.1029/ 2009GL039035.

Laxon, S. W., and Coauthors, 2013: CryoSat-2 estimates of Arctic sea ice thickness and volume. Geophys. Res. Lett., 40, 732-737, https://doi.org/10.1002/grl.50193.

Leppäranta, M., 2005: The Drift of Sea Ice. Springer-Verlag, 266 pp., https://doi.org/10.1007/b138386.

Lindsay, R., and J. Zhang, 2006: Assimilation of ice concentration in an ice-ocean model. J. Atmos. Oceanic Technol., 23, 742749, https://doi.org/10.1175/JTECH1871.1.
- M. Wensnahan, A. Schweiger, and J. Zhang, 2014: Evaluation of seven different atmospheric reanalysis products in the Arctic. J. Climate, 27, 2588-2606, https://doi.org/10.1175/ JCLI-D-13-00014.1.

Liu, Y., and J. R. Key, 2014: Less winter cloud aids summer 2013 Arctic sea ice return from 2012 minimum. Environ. Res. Lett., 9, 044002, https://doi.org/10.1088/1748-9326/9/4/044002.

Madec, G., 2016: NEMO ocean engine. Note du Pôle de modélisation, Institut Pierre-Simon Laplace, Tech. Rep. 27, ISSN 1288-1619, 396 pp., https://www.nemo-ocean.eu/wp-content/ uploads/NEMO_book.pdf.

Miles, M. W., D. V. Divine, T. Furevik, E. Jansen, M. Moros, and A. E. J. Ogilvie, 2014: A signal of persistent Atlantic multidecadal variability in Arctic sea ice. Geophys. Res. Lett., 41, 463-469, https://doi.org/10.1002/2013GL058084.

Ogi, M., S. Rysgaard, and D. G. Barber, 2016: Importance of combined winter and summer Arctic Oscillation (AO) on September sea ice extent. Environ. Res. Lett., 11, 034019, https://doi.org/10.1088/1748-9326/11/3/034019.

Park, H.-S., and A. L. Stewart, 2016: An analytical model for winddriven Arctic summer sea ice drift. Cryosphere, 10, 227-244, https://doi.org/10.5194/tc-10-227-2016.

— S. Lee, Y. Kosaka, S.-W. Son, and S.-W. Kim, 2015: The impact of Arctic winter infrared radiation on early summer sea ice. J. Climate, 28, 6281-6296, https://doi.org/10.1175/JCLI-D14-00773.1.

Rampal, P., J. Weiss, C. Dubois, and J. Ğ. M. Campin, 2011: IPCC climate models do not capture Arctic sea ice drift acceleration: Consequences in terms of projected sea ice thinning and decline. J. Geophys. Res., 116, C00D07, https://doi.org/10.1029/ 2011JC007110.

Renner, A. H. H., S. Gerland, C. Haas, G. Spreen, J. F. Beckers, E. Hansen, M. Nicolaus, and H. Goodwin, 2014: Evidence of Arctic sea ice thinning from direct observations. Geophys. Res. Lett., 41, 5029-5036, https://doi.org/10.1002/2014GL060369.

Rienecker, M. M., and Coauthors, 2011: MERRA: NASA's modern-era retrospective analysis for research and applications. J. Climate, 24, 3624-3248, https://doi.org/10.1175/JCLID-11-00015.1.

Rigor, I. G., J. M. Wallace, and R. L. Colony, 2002: Response of sea ice to the Arctic Oscillation. J. Climate, 15, 2648-2663, https:// doi.org/10.1175/1520-0442(2002)015<2648:ROSITT>2.0.CO;2.

Screen, J. A., I. Simmonds, and K. Keay, 2011: Dramatic interannual changes of perennial Arctic sea ice linked to abnormal summer storm activity. J. Geophys. Res., 116, D15105, https:// doi.org/10.1029/2011JD015847.

Serreze, M. C., and Coauthors, 2003: A record minimum arctic seaice extent and area in 2002. Geophys. Res. Lett., 30, 1110, https://doi.org/10.1029/2002GL016406.

Smedsrud, L. H., M. H. Halvorsen, J. C. Stroeve, R. Zhang, and K. Kloster, 2017: Fram Strait sea ice export variability and September Arctic sea ice extent over the last 80 years. Cryosphere, 11, 65-79, https://doi.org/10.5194/tc-11-65-2017.

Smith, R., and Coauthors, 2010: The Parallel Ocean Program (POP) reference manual: Ocean Component of the Community Climate System Model (CCSM) and Community Earth System Model (CESM). Tech. Rep. LAUR-10-01853, Los Alamos National Laboratory, Los Alamos, NM, 141 pp., http://www.cesm. ucar.edu/models/cesm1.0/pop2/doc/sci/POPRefManual.pdf.

Stroeve, J. C., J. Maslanik, M. C. Serreze, I. Rigor, W. Meier, and C. Fowler, 2011: Sea ice response to an extreme negative phase of the Arctic Oscillation during winter 2009/2010. Geophys. Res. Lett., 38, L02502, https://doi.org/10.1029/2010GL045662. 
Thompson, D. W. J., and J. M. Wallace, 1998: The Arctic Oscillation signature in the wintertime geopotential height and temperature fields. Geophys. Res. Lett., 25, 1297-1300, https:// doi.org/10.1029/98GL00950.

Thorndike, A. S., 1992: A toy model linking atmospheric thermal radiation and sea ice growth. J. Geophys. Res., 97, 9401-9410, https://doi.org/10.1029/92JC00695.

- and R. Colony, 1982: Sea ice motion in response to geostrophic winds. J. Geophys. Res., 87, 5845-5852, https://doi.org/ 10.1029/JC087iC08p05845.

Tietsche, S., M. A. Balmaseda, H. Zuo, and K. Mogensen, 2015: Arctic sea ice in the global eddy-permitting ocean reanalysis ORAP5. Climate Dyn., 49, 775-789, https://doi.org/10.1007/ s00382-015-2673-3.

Tilling, R. L., A. Ridout, A. Shepherd, and D. J. Wingham, 2015: Increased Arctic sea ice volume after anomalously low melting in 2013. Nat. Geosci., 8, 643-646, https://doi.org/10.1038/ngeo2489.

Wang, J., J. Zhang, E. Watanabe, M. Ikeda, K. Mizobata, J. E. Walsh, $\mathrm{X}$. Bai, and B. Wu, 2009: Is the dipole anomaly a major drier to record lows in Arctic summer sea ice extent? Geophys. Res. Lett., 36, L05706, https://doi.org/10.1029/2008GL036706.

Weeks, W. F., and S. F. Ackley, 1986: The growth, structure, and properties of sea ice. The Geophysics of Sea Ice, N. Untersteiner, Ed., NATO ASI Series, Vol. 146, Springer, 9164, https://doi.org/10.1007/978-1-4899-5352-0_2.
Williams, J., B. R. Tremblay, R. Newton, and R. Allard, 2016: Dynamic preconditioning of the minimum September sea-ice extent. J. Climate, 29, 5879-5891, https://doi.org/10.1175/JCLID-15-0515.1.

Wingham, D. J., and Coauthors, 2006: CryoSat: A mission to determine the fluctuations in Earth's land and marine ice fields. $A d v$. Space Res., 37, 841-871, https://doi.org/10.1016/j.asr.2005.07.027.

Woods, C., R. Caballero, and G. Svensson, 2013: Large scale circulation associated with moisture intrusions into the Arctic during winter. Geophys. Res. Lett., 40, 4717-4721, https://doi.org/ 10.1002/grl.50912.

Zhang, J., and D. A. Rothrock, 2003: Modeling global sea ice with a thickness and enthalpy distribution model in generalized curvilinear coordinates. Mon. Wea. Rev., 131, 845-861, https://doi.org/10.1175/1520-0493(2003)131<0845: MGSIWA $>2.0 . \mathrm{CO} ; 2$

Zib, B., X. Dong, B. Xi, and A. Kennedy, 2012: Evaluation and intercomparison of cloud fraction and radiative fluxes in recent reanalyses over the Arctic using BSRN surface observations. J. Climate, 25, 2291-2305, https://doi.org/10.1175/ JCLI-D-11-00147.1.

Zuo, H., M. A. Balmaseda, and K. Mogensen, 2015: The new eddypermitting ORAP5 ocean reanalysis: Description, evaluation and uncertainties in climate signals. Climate Dyn., 49, 791-811, https://doi.org/10.1007/s00382-015-2675-1. 